\title{
Analisis End-User Computing Satisfaction pada Online Public Access Catalogue "Izylib" di Lingkungan Universitas Jenderal Soedirman
}

\author{
Anisa Sri Restanti ${ }^{1}$; Endah Yuni Astuti ${ }^{2}$; \\ Munjiati $^{3}$; Utik Nurwijayanti ${ }^{4}$; Sayekti Widianingtias ${ }^{5}$ \\ ${ }^{12345}$ Pustakawan pada Perpustakaan Universitas Jenderal Soedirman \\ 1anisasrirestanti@gmail.com
}

\begin{abstract}
Abstrak
Pada masa ini, dunia kepustakawanan mengalami masa transisi yang sangat besar terlihat dari sisi koleksi, sumber daya manusia, serta fasilitas fisik perpustakaan. Online Public Access Catalogue (OPAC) merupakan salah satu fasilitas penelusuran informasi yang diberikan untuk memudahkan temu kembali informasi di perpustakaan. Terdapat berbagai tampilan OPAC sesuai dengan software yang digunakan. Sejak tahun 2011 Perpustakaan di lingkungan Unsoed memberikan fasilitas OPAC Izylib. Meskipun demikian, sampai saat ini belum pernah dilakukan sebuah kajian mengenai kepuasan pemustaka terhadap pemanfaatan fasilitas tersebut. Kajian ini menggunakan metode survei dengan pendekatan kuantitatif dan tipe deskriptif dengan model analisis end-user computing satisfaction. Tujuan penelitian ini menganalisis tingkat kepuasan pemustaka dalam memanfaatkan OPAC Izylib di lingkungan Unsoed. Hasil penelitian menunjukkan tingkat kepuasan pemustaka terhadap Online Public Access Catalogue "Izylib" di lingkungan Universitas Jenderal Soedirman berada pada kategori puas ditunjukkan dengan nilai mean 92,26. Berdasarkan temuan tersebut pengelola perpustakaan khususnya tim TI hendaknya dapat melakukan evaluasi sehinga tingkat kepuasan pemustaka terhadap pemanfaatan OPAC meningkat menjadi sangat puas.
\end{abstract}

Katakunci: Library service; OPAC; Information retrieval; End-user computing satisfaction 


\section{Pendahuluan}

Pada era ini, dunia kepustakawanan mengalami masa transisi yang sangat besar dilihat dari sisi koleksi, sumber daya manusia, serta fasilitas fisik perpustakaan. Perubahan ini merupakan penyesuaian dari kebutuhan pemustaka maupun karena permasalahan-permasalahan yang terjadi pada saat ini. Perilaku pencari informasi telah mengalami pergeseran. Salah satu faktor penyebab perubahan ini adalah karakteristik pemustaka khususnya mahasiswa sebagai generasi digital atau dikenal dengan digital native. Generasi ini tidak melihat internet sebagai teknologi, melainkan sebagai bagian kehidupan.

Perpustakaan Universitas Jenderal Soedirman (Unsoed) sebagai salah satu perpustakaan perguruan tinggi tidak terlepas dari tantangan perubahan tersebut. Sejak berdirinya UPT Perpustakaan berusaha memberikan layanan terbaik bagi pemustaka. Perpustakaan terus berusaha memenuhi kebutuhan pemustaka. Selain fokus pada pemanfaatan koleksi, perpustakaan meningkatkan fasilitas fisik yang disesuaikan dengan harapan para pemustaka. Salah satu fasilitas fisik yang disediakan perpustakaan dalam menghadapi perubahan pemustakanya adalah Online Public Access Catalogue (OPAC).

OPAC merupakan salah satu alat bantu temu kembali koleksi yang ada di perpustakaan dengan memanfaatkan teknologi informasi. Pada tahun 2011 UPT Perpustakaan menggunakan software Izylib untuk mengintegrasikan pengelolaan perpustakaan di lingkungan Unsoed. Izylib merupakan aplikasi perpustakaan terintegrasi berbasis web., sehingga memungkinkan setiap pemustaka untuk mengakses OPAC tanpa terbatas waktu dan tempat.

Sejak perpustakaan memberikan fasilitas OPAC hingga saat ini belum pernah melakukan kajian mengenai kepuasan pemustaka pada saat menggunakan OPAC. Dengan mengetahui tingkat kepuasan pemustaka, perpustakaan dapat memperoleh informasi yang dapat digunakan untuk melakukan evaluasi dalam memberikan pelayanan perpustakaan. Berdasarkan hal tersebut, peneliti merasa perlu melakukan kajian dengan rumusan masalah bagaimana tingkat kepuasan pemustaka dalam meng- 
gunakan OPAC “Izylib” di lingkungan Unsoed berdasarkan analisis enduser computing satisfaction. Adapun tujuan penelitian ini adalah untuk menganalisis tingkat kepuasan pemustaka dalam memanfaatkan OPAC "Izylib" di lingkungan Unsoed dengan menggunakan model analisis enduser computing satisfaction.

End-User Computing Satisfaction (EUCS) merupakan salah satu metode pengukuran kepuasan pemustaka sebagai satu bentuk evaluasi sistem informasi yang dikembangkan oleh Doll dan Torkzadeh (1988). Dalam hal ini, menurut Doll dan Torzadeh (1988) adalah perilaku suka (puas) yang ditunjukkan seseorang ketika berinteraksi langsung dengan sebuah aplikasi komputer. Lebih lanjut, Doll dan Torkzadeh melakukan penelitian yang menghasilkan model dalam pengukuran kepuasan pengguna. Model ini menekankan pada kepuasan (satisfaction) pengguna akhir terhadap aspek teknologi, dengan menggunakan lima standar dalam yang digunakan untuk mengukur kepuasan pengguna. Kelima standar tersebut meliputi (1) dimensi content, (2) dimensi accuracy, (3) dimensi format, (4) dimensi ease of use, dan (5) dimensi Timeliness.

Acuan referensi penelitian yang digunakan sebagai pembanding dalam penelitian ini adalah penelitian yang dilakukan oleh Arifah (2014), tujuan penelitian ini mengevaluasi kepuasan pengguna OPAC perpustakaan STIMIK AMIKOM Yogyakarta dengan metode end user computing satisfaction, analisis data yang digunakan importance performance analysis dan Indeks Kepuasan Pengguna (IKP). Hasil penelitian menunjukkan nilai IKP $78,01 \%$ yakni pengguna cukup puas dengan kinerja OPAC. Selanjutnya penelitian yang dilakukan Dalimunthe (2016). Tujuan penelitian ini mengetahui tingkat kepuasan pengguna OPAC dengan menggunakan EUCS pada perpustakaan UIN Suska Riau. Analisis data dilakukan dengan analisis deskriptif menggunakan rentang kategori dan presentasi melalui skala Likert. Hasil penelitian menunjukkan nilai persentasi $74,10 \%$ termasuk dalam kategori setuju-pemustaka merasa puas menggunakan OPAC.

Berdasarkan kajian pustaka tersebut, menunjukkan bahwa penelitian yang akan dilakukan oleh peneliti berbeda dengan penelitian terdahulu. 
Perbedaan penelitian terletak pada rumusan masalah yang diteliti, metode analisis data yang digunakan, subjek, lokasi, serta waktu penelitian.

\section{Metode Penelitian}

Penelitian ini dilakukan di perpustakaan lingkungan Unsoed pada bulan Juli - Oktober 2017. Metode yang digunakan dalam penelitian ini yakni metode survei dengan pendekatan kuantitatif dengan tipe deskriptif. Populasi dalam penelitian ini mahasiswa Unsoed program S1 tahun ajaran 2014/ 2015 dan tahun 2015/2016. Bersumber pada data Bagian Pendidikan Universitas Jenderal Soedirman diketahui terdapat 7376 mahasiswa. Teknik pengambilan sampel menggunakan rumus Isaac dan Michael yang disajikan dalam Sugiyono (2014) dengan tingkat kesalahan 5\% sehinga ditemukan responden 332 mahasiswa. Teknik pengambilan sampel menggunakan teknik purporsive-proportional sampling. Kriteria sampel yang diterapkan oleh peneliti (1) berkunjung ke perpustakaan di lingkungan Unsoed dan pernah menggunakan OPAC IzyLib (2) diperkirakan secara obyektif dapat memberikan informasi mengenai layanan OPAC IzyLib.

Pengumpulan data dilakukan dengan studi literatur, kuesioner, observasi dan wawancara. Validitas alat ukur dilakukan dengan mencari harga korelasi antara bagian dari alat ukur secara keseluruhan menggunakan rumus pearson product moment dan pengujian reliabilitas menggunakan rumus koefisien alpha cronbach. Teknik analisis data yang digunakan dalam penelitian ini adalah analisis deskriptif menggunakan pengujian nilai mean. Selanjutnya, untuk memberikan pemaknaan terhadap skor mean, penulis menyusun pedoman penafsiran menurut pedoman yang dikemukakan Sukiman (2012).

\section{Hasil dan Pembahasan}

Peneliti telah mendistribusikan 332 kuesioner untuk mengumpulkan data primer dalam penelitian ini. Kuesioner tersebut meliputi 25 butir pernyataan. Keseluruhan kuesioner yang didistribusikan kembali kepada 
peneliti sampai batas waktu yang telah ditentukan. Sebagai subyek penelitian adalah mahasiswa S1 tahun ajaran 2014/ 2015 dan tahun 2015/2016.

Data primer yang telah berhasil dikumpulkan kemudian dideskripsikan dengan melakukan pengukuran nilai rata-rata hitung pada setiap aspek untuk memberikan gambaran data yang diperoleh. Hasilnya disajikan dalam bentuk tabel. Selanjutnya, peneliti memberikan pemaknaan terhadap skor pada lima dimensi End-User Computing Satisfaction. Berdasarkan hasil analisis data, peneliti mendapatkan suatu kesimpulan yang dapat dimanfaatkan (generalisasi) untuk populasi. Berikut ini pemaparan hasil penelitian.

\section{Implementasi sistem Izylib di UPT Perpustakaan Unsoed}

UPT Perpustakaan Universitas Jenderal Soedirman (Unsoed), sebagai salah satu jenis perpustakaan perguruan tinggi terus berusaha memanfaatkan teknologi informasi dalam pengelolaan sumberdaya yang ada. Dalam kurun waktu 20 tahun, sedikitnya telah tiga kali UPT Perpustakaan Unsoed berganti software. Software tersebut Siprus, SIPISIS, dan sekarang Izylib.

Izylib, merupakan software terintegrasi berbasis web. Aplikasi ini mengintegrasikan pengelolaan UPT Perpustakaan dan perpustakaan fakultas di lingkungan Unsoed, termasuk koleksinya, sehingga meta data semua koleksi ada di Izylib sehingga terpantau dan dapat dikendalikan melalui sistem ini. Software ini mampu mengakomodasi berita, variasi koleksi, artikel, usulan koleksi, pendaftaran, serta saran dan kritik. Menu utama meliputi CPANEL, Galery, Saran dan Kritik; Anggota: Pendaftaran, Cek Peminjaman; Links: ke beberapa alat web E- journal yang dilanggan perpustakaan. 


\section{Gambar 1. Tampilan OPAC Izylib}

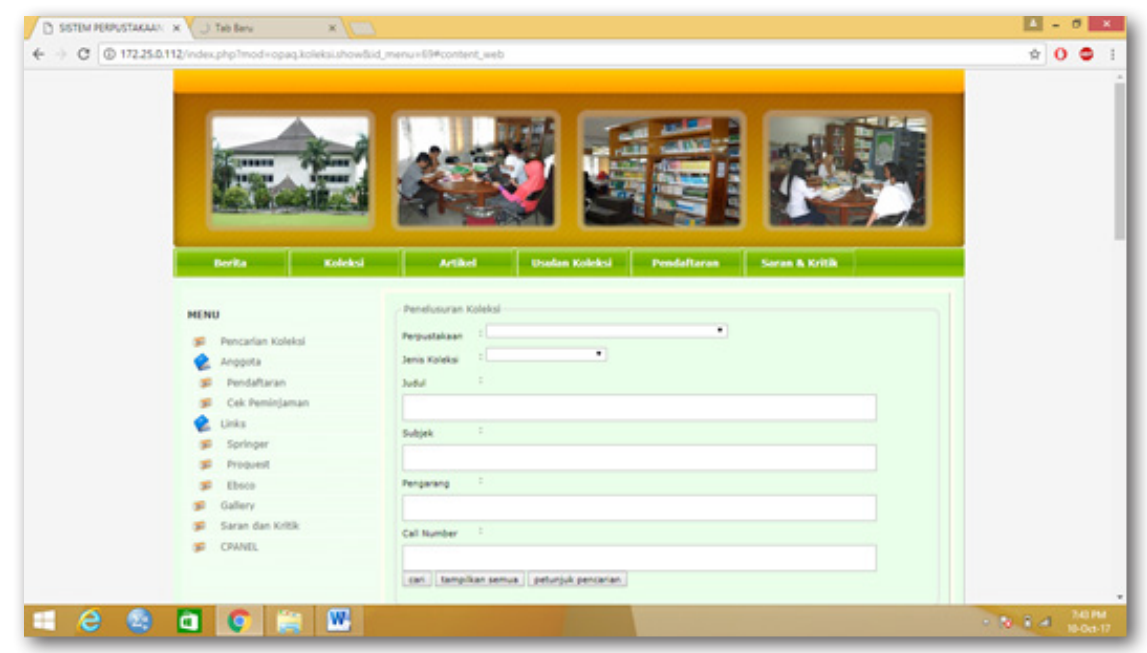

Sumber: lib.unsoed.ac.id, 2017

\section{Karakteristik Responden}

Responden dalam penelitian ini adalah mahasiswa S1 tahun ajaran 2014/ 2015 dan tahun 2015/2016 . Bedasarkan rumus Isaac dan Michael yang disajikan dalam Sugiyono (2014) dengan tingkat kesalahan 5\% sehinga ditemukan responden 332 mahasiswa. Responden diidentifikasikan menurut jenis kelamin. Adapun identifikasi responden sebagai berikut.

Tabel 1. Deskripsi Responden Berdasarkan Jenis Kelamin

\begin{tabular}{cccc}
\hline No & Jenis Kelamin & Frekuensi & Persentase \\
\hline 1 & Laki-Laki & 121 & $36 \%$ \\
\hline 2 & Perempuan & 211 & $64 \%$ \\
\hline & Jumlah & 332 & $100 \%$ \\
\hline
\end{tabular}

Sumber: Data Primer Diolah pada Bulan Oktober, 2017

Berdasarkan tabel di atas, dapat diketahui bahwa deskripsi responden berdasarkan jenis kelamin menunjukkan bahwa responden perempuan dalam 
penelitian ini sebanyak 211 orang atau 64\%, sedangkan laki-laki sebanyak 121 orang atau 36\%. Dengan demikian dapat disimpulkan bahwa responden perempuan lebih banyak dibandingkan dengan responden laki-laki.

\section{Analisis tingkat kepuasan pemustaka dalam pemanfaatan OPAC Izylib menggunakan model analisis end-user computing satisfaction}

Tingkat kepuasan pemustaka dalam pemanfatan OPAC dilakukan dengan menggunakan model analisis end-user computing satisfaction meliputi 5 dimensi selanjutnya diuraikan dalam 25 butir pernyataan kuesioner. Pengujian validitas tiap butir digunakan analisis item, yaitu mengkorelasikan skor tiap butir dengan skor total yang merupakan jumlah tiap skor butir. Syarat minimum untuk dianggap memenuhi syarat adalah kalau $r=0,3$. Hasil uji validasi menunjukkan 25 butir pernyataan valid sehingga memenuhi syarat untuk digunakan analisis penelitian. Hasil uji validitas terlihat dalam tabel 2.

Selanjutnya, uji reliabilitas dilakukan untuk mengetahui instrument yang digunakan tepat. Uji reliabilitas merupakan kesesuaian alat ukur dengan yang diukur sehingga alat ukur dapat dipercaya atau dapat diandalkan. Uji reliabilitas dapat dilakukan secara bersama-sama terhadap seluruh butir pertanyaan. Uji reliabilitas dapat dilihat pada nilai Alpha, jika nilai Alpha Cronbach > 0,60 maka reliabel Sujarweni: 186). Uji reliabilitas dilakukan menggunakan rumus Cronbach's Alpha. Adapun rumus Cronbach's Alpha adalah sebagai berikut:

$$
r_{11}=\left[\frac{k}{k-1}\right]\left[1-\frac{\sum \sigma_{b}^{2}}{V_{t}^{2}}\right]
$$

Hasil uji reliabilitas menunjukkan nilai Alpha cronbach untuk semua variabel bernilai lebih besar dari 0,60 dan dinyatakan reliabel, terlihat pada tabel 3 . 
Tabel 3. Nilai Cronbach's alpha uji reliabilitas

\begin{tabular}{|c|c|}
\hline \multicolumn{2}{|c|}{ Reliability Statistics } \\
\hline Cronbach's Alpha & $\mathrm{N}$ of Items \\
\hline .901 & 25 \\
\hline
\end{tabular}

Tabel 2. Hasil Uji validitas

\begin{tabular}{cccc}
\hline Atribut & Korelasi & p-value & Keterangan \\
\hline P1 & $.523^{* *}$ & .000 & Valid \\
\hline P2 & $.561^{* *}$ & .000 & Valid \\
\hline P3 & $.536^{* *}$ & .000 & Valid \\
\hline P4 & $.507^{* *}$ & .000 & Valid \\
\hline P5 & $.400^{* *}$ & .000 & Valid \\
\hline P6 & $.594^{* *}$ & .000 & Valid \\
\hline P7 & $.557^{* *}$ & .000 & Valid \\
\hline P8 & $.536^{* *}$ & .000 & Valid \\
\hline P9 & $.591^{* *}$ & .000 & Valid \\
\hline P10 & $.561^{* *}$ & .000 & Valid \\
\hline P11 & $.535^{* *}$ & .000 & Valid \\
\hline P12 & $.558^{* *}$ & .000 & Valid \\
\hline P13 & $.562^{* *}$ & .000 & Valid \\
\hline P14 & $.548^{* *}$ & .000 & Valid \\
\hline P15 & $.543^{* *}$ & .000 & Valid \\
\hline P16 & $.473^{* *}$ & .000 & Valid \\
\hline P17 & $.547^{* *}$ & .000 & Valid \\
\hline P18 & $.576^{* *}$ & .000 & Valid \\
\hline P19 & $.543^{* *}$ & .000 & Valid \\
\hline P20 & $.554^{* *}$ & .000 & Valid \\
\hline P21 & $.612^{* *}$ & .000 & Valid \\
\hline P22 & $.618^{* *}$ & .000 & Valid \\
\hline P23 & $.590^{* *}$ & .000 & Valid \\
\hline P24 & $.575^{* *}$ & .000 & Valid \\
\hline P25 & $.533^{* *}$ & .000 & Valid \\
\hline & .000 & .0617 & 2017
\end{tabular}

Sumber: data primer diolah Oktober, 2017 


\section{Analisis tingkat kepuasan pemustaka terhadap dimensi content OPAC Izylib}

Dimensi content mengukur kepuasan pengguna ditinjau dari sisi isi dari suatu sistem. Isi dari sistem biasanya berupa fungsi dan modul yang dapat digunakan oleh pengguna sistem dan juga informasi yang dihasilkan oleh sistem. Dimensi content juga mengukur apakah sistem menghasilkan informasi yang sesuai dengan kebutuhan pengguna. Berdasarkan analisis end user computing satisfaction terlihat tingkat kepuasan pemustaka terhadap content OPAC mendapat nilai mean tertinggi yakni 18,45 berada dalam kategori puas. Dapat dipahami, sebagian besar pemustaka merasa puas bahwa OPAC mendukung proses pelayanan perpustakaan di lingkungan Unsoed ditunjukkan dengan nilai mean 4,14. Hal ini terlihat ketika pemustaka mengakses OPAC dapat melihat isi atau cakupan informasi seluruh koleksi di lingkungan perpustakaan Unsoed yang telah terintegrasi pada program Izylib. Hal tersebut menjadikan pemustaka merasa puas terhadap informasi dalam OPAC karena sesuai dengan kebutuhan ditunjukkan dengan nilai mean 4,06. Disamping itu pemustaka menyampaikan content OPAC menyediakan informasi sesuai kebutuhan ditunjukkan pada nilai mean 3,99. Pemustaka memberikan nilai mean 3,83 pada pernyataan informasi dalam OPAC dapat dipertanggungjawabkan kebenarannya. Meskipun demikian keseragaman informasi mendapat nilai mean terendah yakni 3,79 hal ini terlihat di lapangan adanya perbedaan nomor klasifikasi pada koleksi yang sama. Pengelola perpustakaan khususnya pustakawan hendaknya memiliki kesepakatan dalam penggunaan pedoman klasifikasi sehingga tingkat kepuasan pemustaka menjadi sangat puas. 
Hasil distribusi dimensi content terlihat pada gambar berikut.

Gambar 2. Grafik hasil Distribusi Dimensi Content OPAC Izylib

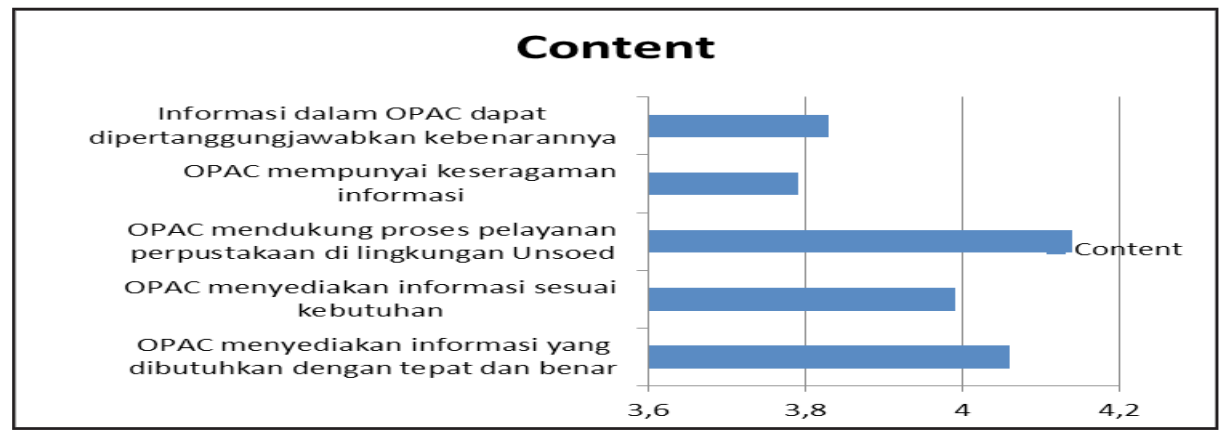

Sumber: data primer diolah Oktober 2017

\section{Analisis tingkat kepuasan pemustaka terhadap dimensi accuracy OPAC Izylib}

Tingkat kepuasan pemustaka dari sisi keakuratan data ketika sistem menerima input kemudian mengolahnya menjadi informasi mendapat nilai mean 17,35 berada dalam kategori puas. Hal ini terlihat ketika pemustaka mendapatkan informasi call number pada sebuah koleksi sebagai pedoman untuk menelusur koleksi secara konvensional, OPAC mampu menyajikan data akurat beberapa koleksi dalam satu waktu yang belum tentu didapat manakala pemustaka bertanya langsung kepada pustakawan. Tingkat kepuasan pemustaka terlihat sebagian besar pemustaka memberikan tanggapan bahwa OPAC memberikan hasil yang sesuai dengan informasi yang dibutuhkan ditunjukkan pada nilai mean 3,88. Pernyataan ketepatan data dalam OPAC dapat diandalkan mendapat nilai mean 3,72. Pemustaka merasa puas terhadap OPAC karena mampu memberikan informasi yang akurat sesuai keinginan ditunjukkan dengan nilai mean 3,67. Selanjutnya pemustaka memberikan nilai mean 3,64 pada pernyataan keakuratan data yang terdapat dalam OPAC lebih terjamin. Pernyatan pemuataka merasa puas dengan keakuratan data dalam OPAC ditunjukkan dengan nilai mean 
3,58. pemustaka merasa puas karena OPAC memberikan hasil sesuai cdengan informasi yang dibutuhkan, ketepatan data dalam OPAC dapat diandalkan serta keakuratan data dalam OPAC lebih terjamin.

Hasil distribusi dimensi accuracy terlihat dalam gambar berikut.

Gambar 3. Grafik hasil Distribusi Dimensi Accuracy OPAC Izylib

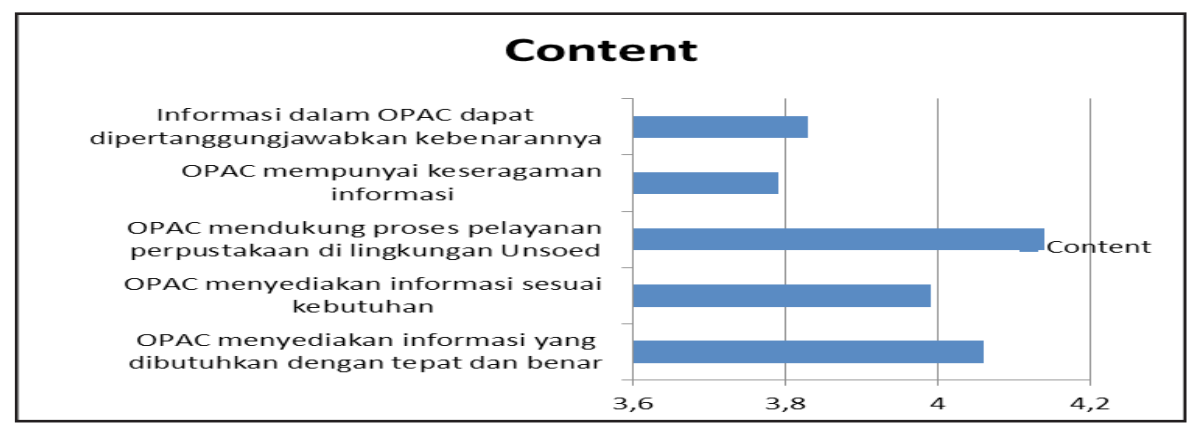

Sumber: data primer diolah Oktober, 2017

\section{Analisis tingkat kepuasan pemustaka terhadap dimensi Format OPAC Izylib}

Kepuasan pemustaka dari sisi tampilan dan estetika dari antarmuka sistem, format dari laporan atau informasi yang dihasilkan oleh sistem atau dimensi format berada pada nilai mean paling rendah yakni 17,05. Berdasarkan pedoman penafsiran rata-rata 17,05 berada pada rentang 17 - 20 termasuk dalam kategori puas. Hal ini dapat dipahami karena terdapat perbedaan pengalaman pemustaka dalam memanfaatkan mesin pencari. Tampilan OPAC hanya dalam format text saja, berbeda dengan tampilan search engine yang menyertakan format gambar dan lainnya. Hal tersebut dipahami pemustaka merasa puas terhadap format OPAC terlihat sebagian besar pemustaka memberikan tanggapan bahwa tampilan OPAC mewakili kebutuhan informasi ditunjukkan dengan nilai mean 3,83. Kepuasan pemuastaka terhadap tampilan OPAC memberikan informasi dengan jelas ditunjukkan dengan nilai mean 3,78. Tata letak tombol navigasi dalam OPAC memenuhi syarat mendapat nilai mean 3,74. Keserasian warna sudah tepat dan menarik mendapat nilai mean 
3,40. Selanjutnya Tampilan OPAC yang tersedia sangat menarik mendapat nilai mean 3,37. Berikut hasil distribusi dimensi format.

Gambar 4. Grafik hasil Distribusi Dimensi Format OPAC Izylib

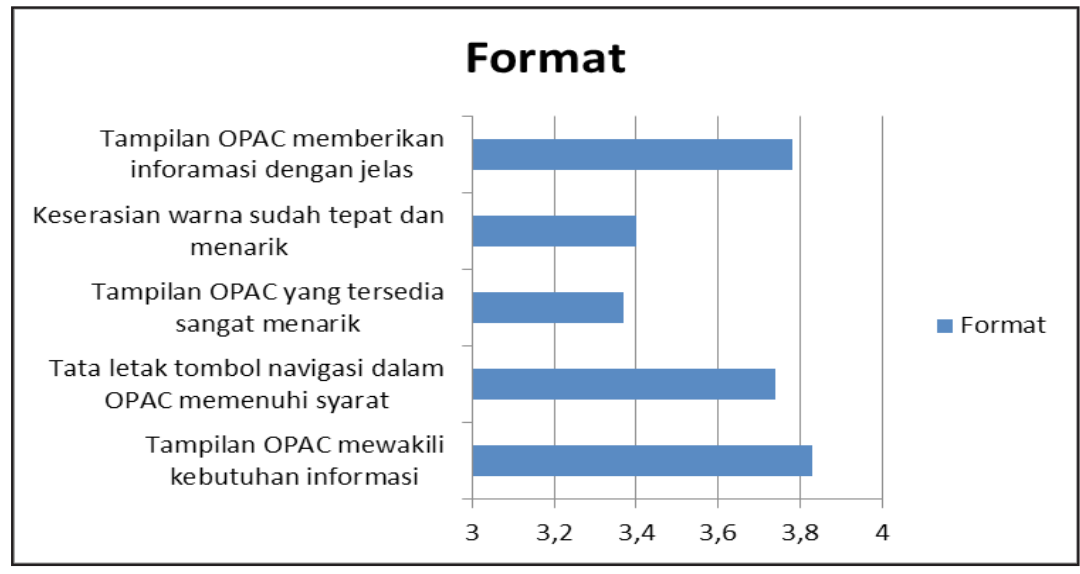

Sumber: data primer diolah Oktober, 2017

\section{Analisis tingkat kepuasan pemustaka terhadap dimensi Ease of Use OPAC Izylib}

Dimensi Ease of Use mengukur kepuasan pengguna dari sisi kemudahan pengguna atau user friendly dalam menggunakan sistem. Deskripsi kepuasan pemuastaka terhadap ease to use OPAC dijabarkan dalam lima aspek mendapat skor rata-rata 17,73 . Berdasarkan pedoman penafsiran rata-rata 17,73 berada pada rentang 17 - 20 termasuk dalam kategori puas. Berdasarkan hasil wawancara dengan pengelola perpustakaan perpustakaan di lingkungan Unsoed selalu mengadakan pendidikan pengguna bagi mahasiswa baru. Salah satu materinya adalah pemanfaatan OPAC hal ini tentu memudahkan pemustaka dalam mengoperasikan OPAC. Sebagian besar pemustaka memberikan tanggapan bahwa penggunaan OPAC mudah dipahami ditunjukkan dengan nilai mean 3,90. Proses login ke OPAC dapat dilakukan dengan mudah dengan nilai mean 3,86. Kepuasan terhadap kemudahan pemanfaatan OPAC ditunjukkan nilai mean 3,82 pada 
pernyataan perpustakaan menyediakan petunjuk pengunaan, terdapat tombol navigasi yang jelas bearada pada nilai mean 3,80 . Selanjutnya pernyataan sistem memberitahu dengan cepat saat terjadi kesalahan pengunaan OPAC mendapat nilai mean 3,80. Berikut hasil distribusi dimensi ease of use.

Gambar 5. Grafik hasil Distribusi Dimensi ease of use OPAC Izylib

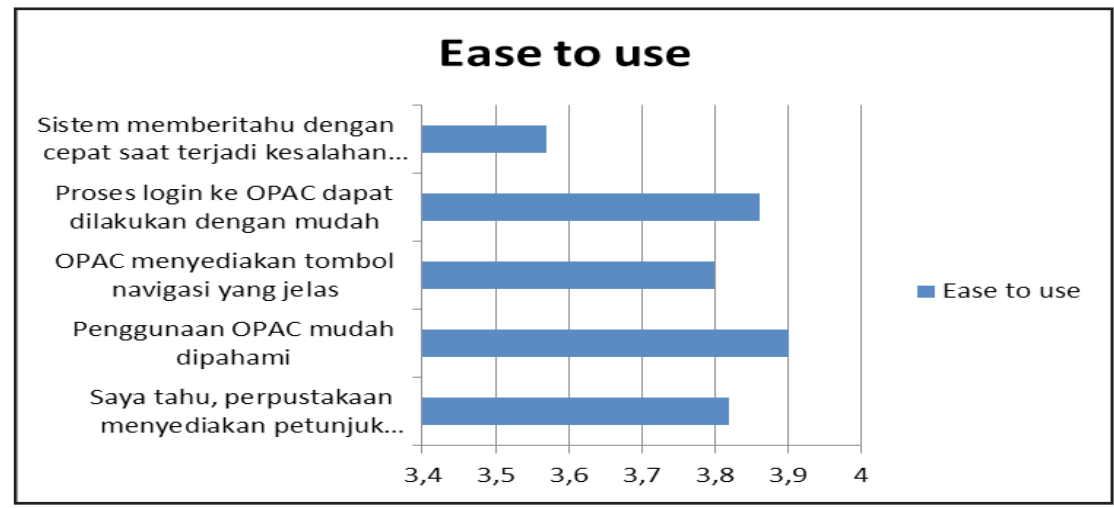

Sumber: data primer diolah Oktober, 2017

\section{Analisis tingkat kepuasan pemustaka terhadap dimensi Timeliness OPAC Izylib}

Dimensi timeliness mengukur kepuasan pemustaka dari sisi ketepatan waktu sistem dalam menyajikan atau menyediakan data dan informasi yang dibutuhkan oleh pengguna. Deskripsi kepuasan pemuastaka terhadap timeliness OPAC dijabarkan dalam lima aspek mendapat skor rata-rata 17,90. Berdasarkan pedoman penafsiran rata-rata 17,90 berada pada rentang $17-20$ termasuk dalam kategori puas. Dengan demikian dapat dipahami pemustaka merasa puas terhadap timeliness OPAC terlihat sebagian besar pemustaka memberikan tanggapan bahwa dengan OPAC pemustaka dapat memperoleh informasi dengan cepat ditunjukkan pada nilai mean 4,04. OPAC secara cepat menjalankan perintah dan menampilkan hasilnya ditunjukkan dengan nilai mean 4,03. Penggunaan OPAC tidak perlu membutuhkan waktu lama untuk mendapat hasilnya ditunjukkan dengan nilai mean 3,95. Penyajian data pada 
penggunaan OPAC tepat waktu dengan nilai mean 3,63. Selanjutnya OPAC memberikan informasi yang up to date mendapat nilai mean 3,52. Berikut hasil distribusi pada dimensi timelines.

Gambar 6. Grafik hasil Distribusi Dimensi Timelines OPAC Izylib

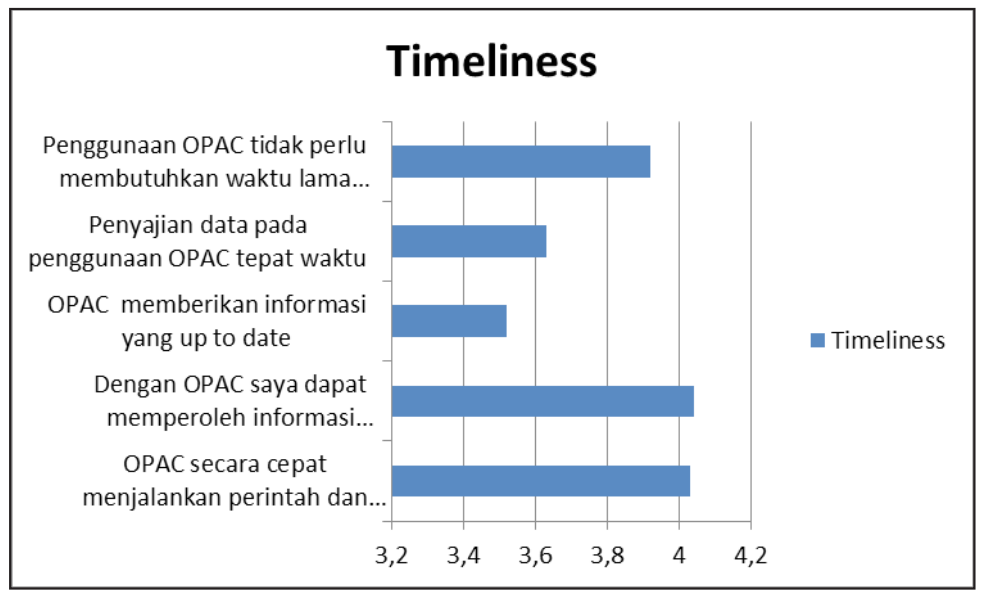

Sumber: data primer diolah Oktober, 2017

Hasil temuan dari penghitungan nilai mean terhadap dimensi content, accuracy, format, ease to use, dan dimensi timelines dapat terlihat lebih jelas dalam gambar berikut ini.

Gambar 7. Grafik hasil Distribusi pada Analisis EUCS

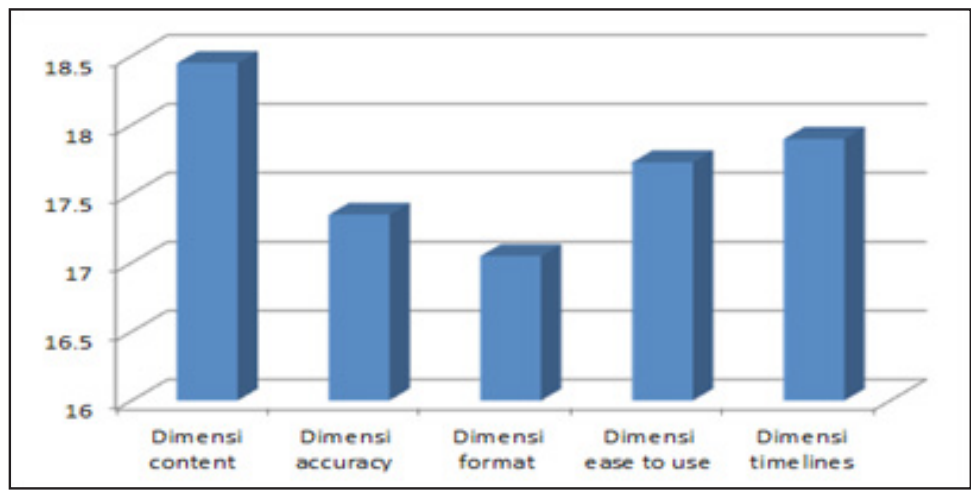

Sumber: data primer diolah Oktober, 2017 
Selanjutnya, peneliti memberikan pemaknaan terhadap skor pada analisis end-user computing satisfaction sesuai pedoman penafsiran yang telah disusun. Pengukuran analisis end-user computing satisfaction menggunakan lima dimensi dan dijabarkan dalam 25 pernyataan, dengan demikian didapat pedoman penafsiran sebagai berikut.

Tabel 4. Pedoman Penafsiran Deskripsi Analisis EUCS

\begin{tabular}{lcrrrr}
\hline \multicolumn{1}{c}{ Kategori } & Interval & Titik Tengah & Frekuensi & Jml & Mean \\
\cline { 1 - 5 } Sangat Puas & $109-129$ & 119 & 1132 & 134708 & \\
\cline { 1 - 5 } Puas & $87-108$ & 97.5 & 4633 & 451717.5 & \\
\cline { 1 - 5 } Cukup Puas & $66-86$ & 76 & 2176 & 165376 & \multirow{2}{*}{92.26} \\
\cline { 1 - 5 } Tidak Puas & $45-65$ & 55 & 300 & 16500 & \\
\cline { 1 - 5 } Sangat tidak Puas & $25-44$ & 34.5 & 138 & 4761 & \\
\cline { 1 - 5 } & & & & &
\end{tabular}

Sumber: data primer diolah Oktober, 2017

Berdasarkan tabel tersebut terlihat skor rata-rata analisis end-user computing satisfaction adalah 92,26. Berdasarkan pedoman penafsiran, rata-rata 92,26 termasuk dalam kategori puas. Dengan demikian dapat dipahami tingkat kepuasan pemustaka terhadap OPAC Izylib di lingkungan perpustakaan Unsoed termasuk dalam kategori puas. Meskipun demikian pengelola perpustakaan khususnya bidang pengembangan teknologi informasi hendaknya memperbaiki keakuratan, kemudahan, dan dari sisi isi OPAC, terutama format OPAC sehingga kepuasan pemustaka dapat naik menjadi sangat puas.

\section{Kesimpulan dan Saran}

Berdasarkan hasil temuan penelitian yang telah dilakukan dapat diambil kesimpulan bahwa analisis tingkat kepuasan pemustaka terhadap Online Public Access Catalogue "Izylib" di Lingkungan Universitas Jenderal Soedirman berada pada kategori puas ditunjukkan dengan nilai mean 92,26. Temuan dalam penelitian ini menunjukkan dimensi format pada Online Public Access Catalogue "Izylib" di lingkungan Universitas Jenderal 
Soedirman berada pada kategori puas dengan nilai mean terendah 17,05 dibandingkan dimensi lainya. Dengan demikian peneliti memberikan saran kepada pengelola perpustakaan khususnya tim TI hendaknya dapat melakukan evaluasi terhadap format OPAC sehinga tingkat kepuasan pemustaka terhadap pemanfaatan OPAC meningkat menjadi sangat puas.

\section{Ucapan Terima Kasih}

Terima kasih kepada Lembaga Penelitian dan Pengabdian Kepada Masyarakat Universitas Jenderal Soedirman atas dukungan pendaannya melalui hibah sehingga penelitian ini dapat terselesaikan tepat waktu.

\section{Daftar Pustaka}

Arifah, Fatimah Nur, Abidarin Rosidi, \& Hanif Al Fatta. Evaluasi Kepuasan Pelayanan Pengguna Aplikasi OPAC Perpustakaan STIMIK AMIKOM Yogyakarta. Citec Journal 1 (1): 46-56

Bungin, Burhan. 2006. Metodologi Penelitian Kuantitatif: komunikasi, ekonomi, dan kebijakan publik sderta ilmu-ilmu sosial lainnya. Jakarta: Kencana.

Dalimunthe, Nurmaini, \& Cici Ismiati. 2016. Analisis Tingkat Kepuasan Pengguna Online Public Acces Catalog (OPAC) dengan Metode EUCS studi kasus Perpustakaan UIN SUSKA Riau. Jurnal Rekayasa dan Manajemen Informasi 2 (01): 71-75

Doll, W. J., Xia, W., \& Torkzadeh, G. 1994. A confirmatory factor analysis of the end-usercomputing satisfaction instrument. MIS Quarterly, December, 453-461.

Doll, W. J., \& Torkzadeh, G. 1988. The measurement of end-user computing satisfaction. MIS Quarterly, June, 259-274.

Sujarweni, V. Wiratna dan Poly Endrayanto. 2012.Statistika untuk Penelitian, Yogyakarta: Graha Ilmu,

Sukiman. 2012. Pengembangan Sistem Evaluasi. Yogyakarta: Insan Madani Sugiyono. 2014. Metode Penelitian Kuantitatif Kualitatif dan R\&D, Bandung: Alfabeta.Torkzadeh, G.,\&Doll, D. J. 1991.Test-retest reliability of the end-user computing satisfaction instrument. Decision Sciences, 22, 26-37. 